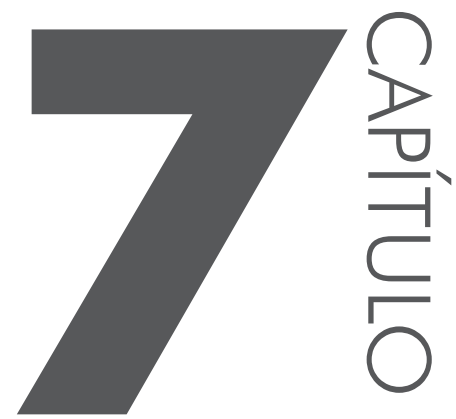

\title{
A PRECARIZAÇÃO DO TRABALHO NO LIMIAR DO SÉCULO XXI
}

Edson Benedito Santana ${ }^{1}$

Carmem Lúcia Costa ${ }^{2}$

Resumo: Este artigo apresenta algumas reflexões realizadas na pesquisa de mestrado em Geografia da Universidade Federal da Goiás - Regional Catalão, e busca compreender o grau de precarização do homem que trabalha em meio aos reformulados locais de trabalho, estabelecendo um elo de diálogo com o processo oriundo no chão da fábrica e que hoje alcança a vida do trabalhador em outros espaços, pois as implicações da precarização do trabalho para a classe trabalhadora

1 Programa de Pós-graduação em Geografia, Unidade Acadêmica Especial de Geografia, Universidade Federal de Goiás/Regional Catalão, Catalão - GO, Brasil

2 Programa de Pós-graduação em Geografia, Unidade Acadêmica Especial de Geografia, Universidade Federal de Goiás/Regional Catalão, Catalão - GO, Brasil

E-mail de contato: geovidaedson@gmail.com; clcgeo@gmail.com 
no limiar do século XXI são verificadas para além do chão de fábrica. Assim, na busca pelo referido objetivo, construímos, acerca da classe trabalhadora da Mitsubishi Motors Company do Brasil (MMCB) situada em Catalão (GO), inquietações geográficas derivadas desses "novos” espaços da precarização. Ao caminhar de encontro a esta realidade, apontamos, através da pesquisa bibliográfica, o alcance do capital na vida do trabalhador genérico. Como resultados preliminares deste estudo, verifica-se o conhecimento da área da pesquisa a partir de fontes bibliográficas que evidenciam o panorama da exploração e expropriação dos sujeitos através dos ritmos acelerados de trabalho, fornecendo suporte para o entendimento do mesmo, fortalecendo, assim, o debate em torno do movimento de precarização do trabalho que vem paulatinamente sendo intensificado.

Palavras-chave: precarização; trabalho; vida cotidiana.

Abstract: This article presents some of the reflections made on the master's research in Geography / UFG / RC and seeks to understand the degree of insecurity of man-to-work among the local reformulated restructured work, establishing a dialogue link between the process originated in shop floor and that today reaches the worker's life in other spaces. In this sense, the implications of job insecurity for the working class in the XXI century threshold are verified beyond the factory floor. So in the quest to achieve that goal, we build on the working class of Mitsubishi Motors Company of Brazil (MMCB) located in Catalan (GO) geographical concerns, derived from these "new" spaces of insecurity. When walking against this reality pointed out by literature, the capital of reach in the life of the generic individual working. As preliminary results of this study can verify the knowledge of the research area from literature sources, which show the picture of the exploitation and expropriation of the subject through the accelerated working time, as well as provide support for its understanding, thus strengthening the debate around the casualization of labor movement that is gradually being intensified.

Keywords: precariousness; work; everyday life.

\section{INTRODUC̣ÃO}

Ao propor uma leitura geográfica da precarização do trabalho no século XXI, inúmeras situações se colocam, dentre as quais os limites desta precarização e os "novos" espaços onde esse movimento se materializa dentro e fora dos lugares de trabalho, alcançando a vida em sua cotidianidade, programando espaços e usos destes para a reprodução do capital.

Neste sentido, a compreensão do processo de precarização do trabalho, bem como dos níveis desta precarização, faz-se fundamental, pois esse processo conduz a uma construção histórica, a qual permite chegar ao atual período de precarização do trabalho de forma clara, para enxergar a apropriação destes "novos" 
lugares e as reformuladas formas de apropriação do sujeito que trabalha. Assim, com o objetivo de compreender a forma atual de precarização do trabalho, faz-se necessário compreender o posicionamento histórico do sistema produtor de mercadorias frente ao trabalho e suas formas de reestruturação ao longo da história.

Observa-se um movimento em que o(a) trabalhador(a), além de ser a peça de absorção das crises do sistema produtor de mercadorias, também vem se configurando como responsável pelo período que a antecede, tendo a incumbência de regular, com sua inserção no desregulado mercado de trabalho, o sistema produtor de mercadoria. Este, por sua vez, tende a se manter em movimento, pois é constituído de um processo em desenvolvimento. Daí a necessidade de o processo de trabalho ser mais rígido em um momento e mais flexível em outro, sendo que, atualmente, a vida do(a) trabalhador(a) deve se adaptar às exigências do capital.

Contudo, essa desregulamentação da força de trabalho, ao mesmo tempo em que supre o sistema produtor de mercadorias, impõe ao trabalhador novos contextos de apropriação, para além do chão da fábrica, com estratégias de captura que alcançam a vida cotidiana e ressignificam lugares, informações, práticas, valores e a própria cultura operária.

Este(a) trabalhador(a), que ao longo da história teve de se modelar ao sistema do capital, hoje se vê em meio a um cenário produtor de mercadorias fragilizado, oscilante, rotina que o(a) conduz a uma nova lógica na relação capital versus trabalho, onde o(a) trabalhador(a) é tido como peça de absorção, anterior e posterior aos momentos de crise estrutural. $\mathrm{O}(\mathrm{a})$ trabalhador(a) não está mais incumbido(a) "apenas" de absorver os efeitos posteriores das crises, sejam elas periódicas ou não, como de fato ocorreu ao longo da história, mas sim de evitá-las ou ao menos retardá-las de forma a protelar o resultado da mesma. Dessa forma, observamos uma exploração da força de trabalho em níveis ainda mais extremos e perversos, não apenas passando ao(a) trabalhador(a) a responsabilidade pelos momentos de crise, mas também obrigando-o(a) a viver uma vida ameaçada cotidianamente pelo desemprego, alienando-o(a) cada vez mais.

Portanto, não mais o(a) trabalhador(a) é “convocado(a)" a arcar com os resultados negativos da crise, seja de forma direta com a diminuição da presença do Estado, seja de forma indireta com os financiamentos estatais a empresas privadas, mas é convocad(a) a proporcionar um cenário favorável ao sistema produtor de mercadorias em todos os seus atos, dentro e fora da fábrica. Com o intuito de analisar melhor essa condição, a pesquisa pretende avaliar as transformações ocorridas na indústria automobilística - MMC Motors - em Catalão, no sudeste de Goiás, a partir da reestruturação produtiva e da vida cotidiana dos(as) trabalhadores(as) desta empresa, observando as estratégias para capturar a subjetividade do(a) trabalhador(a) e revertê-la a favor do acúmulo do capital. 
Neste artigo, apresentam-se reflexões iniciais sobre o processo em questão, como resultado de um levantamento bibliográfico que objetiva ampliar os horizontes da análise teórica sobre o mundo do trabalho, sobre a reestruturação produtiva e sobre a captura da subjetividade do(a) trabalhador(a) no contexto atual.

Nas últimas décadas do século XX, iniciou-se uma nova fase no que tange à relação capital versus trabalho, um novo modelo/modo de composição da estrutura precarizante do trabalho, sendo tal evolução proporcionada, em grande medida, pelas novas técnicas e mecanismos modeladores do sistema vigente. Nesse sentido, caracterizar o trabalho no início do século XXI nesses novos territórios se faz de suma importância, tendo em vista que constitui o resultado do movimento iniciado em meados do século XX, com o acúmulo de toda a história humana.

\title{
2 PRECARIZAC̣ÃO do tRABALHO
}

Para avançar na compreensão da transformação da subjetividade do(a) trabalhador(a), seguimos o caminho metodológico indicado por Santos (1996), que aponta a necessidade da compreensão da totalidade a partir da revisão dos lugares e da pesquisa empírica. De acordo com o autor,

\begin{abstract}
Em nosso ponto de vista, um caminho seria partir da totalidade concreta como ela se apresenta neste período de globalização - uma totalidade empírica - para examinar as relações efetivas entre a Totalidade-Mundo e os Lugares. Isso equivale a revisitar o movimento do universal para o particular e vice-versa, reexaminando, sob esse ângulo, o papel dos eventos e da divisão do trabalho como uma mediação indispensável (SANTOS, 1996, p. 92).
\end{abstract}

A economia capitalista baseia-se em uma profunda divisão territorial do trabalho, produzindo mercadorias através da exploração da mão de obra do(a) trabalhador(a) na extração da mais valia. Essa divisão territorial possibilita uma exploração mais intensa, pois se aproveita dos diferentes valores atribuídos ao trabalho em diferentes lugares e, também, de um intercâmbio intenso, fortalecendo o sistema de trocas e acúmulo de capital.

Com o capitalismo, tem início o processo de globalização da economia com aumento da integração dos mercados e a possibilidade de uma compensação de gastos em um determinado lugar de produção por ganhos em outros lugares de distribuição e trocas, interligando cada vez mais o globo. Ainda de acordo com Santos (1996), os reflexos no local são imediatos, pois estes necessitam ser integrados dentro da lógica global a qualquer custo, mesmo que, para tanto, a subjetividade do(a) trabalhador(a) tenha que ser cada vez mais capturada, aprofundando a alienação.

Ao longo desse processo, o capitalismo elabora várias estratégias no sentido de reverter a queda da taxa de lucros e superar as crises que marcam esse sistema. 
Harvey (1992) aponta vários momentos, como o fordismo, o taylorismo e a acumulação flexível, que marcam o período atual de grande expansão do capital, mesclando diversas formas de organização do trabalho em estágios diferentes. Essa fase do capital é o cenário da implantação de várias fábricas nas periferias do sistema produtivo, como no Brasil, e na periferia do sistema produtivo brasileiro, como em Catalão. Tal desconcentração industrial rearticula os lugares dentro de uma lógica distante e transforma as paisagens e a vida cotidiana da classe trabalhadora. Santos (1996, p. 108) lembra que "esta divisão territorial do trabalho cria uma hierarquia entre lugares e, segundo a sua distribuição espacial, redefine a capacidade de agir de pessoas, firmas e instituições”. Acrescentamos que essa ação é sempre mediada pela troca, o que sugere uma leitura desses lugares a partir da lógica de mercado e das estratégias de sobrevivência destes e dos sujeitos aí incluídos.

As estratégias de reprodução da lógica capitalista na acumulação flexível são marcadas por perdas para a classe trabalhadora. Neste sentido, Alves destaca que:

[...] a flexibilização da força de trabalho expressa a necessidade imperiosa de o capital subsumir ou, ainda, submeter e subordinar o trabalho assalariado à lógica da valorização. Através da perpétua sublevação da produção (e reprodução) de mercadorias, inclusive, e principalmente, na flexibilização dos processos de trabalho, dos mercados de trabalho. É por isso que a "acumulação flexível” se apoia, principalmente, na flexibilidade dos processos de trabalho, dos mercados de trabalho e, ainda, dos produtos e padrões de consumo (ALVES, 2013, p. 88).

O trabalho flexível, precário, desregulado, torna-se ferramenta de contingenciamento das crises do sistema produtor de mercadoria. Nesse sentido, são cada vez maiores as exigências para a inserção e permanência no mercado de trabalho, onde a regra é ser um(a) trabalhador(a) que se adapte rapidamente às necessidades da empresa e das leis trabalhistas, suficientemente flexibilizados para cortar direitos e aumentar exigências. Os postos de trabalho são cada vez mais precários, com intensas jornadas e, em alguns casos, condições insalubres de trabalho que, agora desregulado, pode ser cada vez mais explorado. Ainda segundo Alves (2013, p. 89), “o trabalho flexível impõe-se como principal característica do novo e precário mundo do trabalho", sendo, assim, o responsável pelo atual quadro da precarização do trabalho.

A classe trabalhadora passa por um profundo processo de reestruturação e ressignificação, processo que se reflete nas condições de vida cada vez mais difíceis em todo o planeta, com aumento da pauperização e de trabalhos precários, parciais, temporários, com baixos salários e poucos direitos. Também os lugares de trabalho, principalmente os de atividades informais, estão cada vez mais insalubres.

O aumento do número de mulheres no mercado de trabalho também aponta para esta precarização por constituir uma força de trabalho mais barata, 
contribuindo para uma queda geral de salários. A desregulamentação do trabalho, principalmente em empresas terceirizadas de vários ramos, aponta para outra perda de direitos trabalhistas. Associado a isso, o trabalho parcial e doméstico mostra como ainda há espaço para a expansão do capital com ganhos consideráveis. O capital reinventa formas arcaicas de produção para sobreviver e reelabora práticas cotidianas na promoção da troca, como as feiras por exemplo.

A territorialização desse processo de flexibilização no interior de Goiás pode ser observada a partir de empresas como a MMC - Motors, a Vale fertilizantes, a Anglo American, a John Deere, dentre outras na cidade de Catalão. Nesse processo, observamos o deslocamento do capital industrial para o interior do país em busca de mais espaço - e menores custos -, de incentivos fiscais oferecidos pelo Estado - no caso de Goiás, tem-se uma forte política de isenções que funciona como atrativo entre os estados da federação, o que Santos (1996) chama de "guerra dos lugares" - e, é claro, em busca de mão de obra mais barata, no caso, camponeses(as) expulsos(as) pela modernização do campo e pelo avanço do agronegócio na região. As vantagens são inúmeras para o capital. De acordo com Santos,

Todos os lugares existem em relação com um tempo do mundo, tempo do modo de produção dominante, embora nem todos os lugares sejam, obrigatoriamente, atingidos por ele. Ao contrário, os lugares se diferenciam, seja qual for o período histórico, pelo fato de que são diversamente alcançados, seja quantitativamente, seja qualitativamente, por esses tempos no mundo. O tempo do mundo seria o tempo mais externo, abrangente de todos os espaços, independentemente de escala. Haveria, nessa hierarquia e nessa ordem, tempos do Estado-Nação e tempos dos lugares (SANTOS, 1996, p. 111).

Nem sempre o tempo dos lugares é o mesmo tempo do capital, e há um processo de enfrentamento que se estabelece entre os sujeitos com seus interesses e os interesses da troca, da produção. O lugar responde à lógica normativa com o movimento que revela que nem tudo foi cooptado, capturado apesar das investidas cotidianas para que tal processo se realize. Um exemplo é a luta do movimento sindical e sua consolidação no sudeste do estado de Goiás, que contribui com o movimento operário nacional e com o enfrentamento da exploração. Outro ponto de enfrentamento são os movimentos sociais organizados na luta pela terra como o movimento camponês popular -, que se articulam no campo e na cidade, apoiando as ações dos(as) trabalhadores(as) em todas as esferas. Mas sabemos que a luta acontece em níveis desiguais e o capital efetua forte ofensiva na captura da vida do(a) trabalhador(a).

Os problemas mencionados ao longo do artigo esclarecem algumas ações do capital, permitindo uma análise mais criteriosa a respeito de uma empresa 
mundialmente conhecida, muito preocupada em garantir as condições de geração e de reprodução do lucro. Todavia, o reconhecimento dos(as) trabalhadores(as) enquanto classe oportuniza a construção de um novo Brasil e, nesse caso, corroboramos a tese de Thomaz Junior (2011):

Longe de modelos fáceis que podem cumprir papéis predefinidos, pensar um projeto para o Brasil nos põe atentos às lacunas da ausência da crítica radical das experiências tecnocráticas, burocráticas, de sorte que o marxismo continua como referência de vida, de concepção de mundo e fundamento para a construção revolucionária. Em síntese, trata-se de transformar não só as relações de produção, as relações de propriedade, mas também a estrutura das forças produtivas e do aparelho produtivo. Para nós, é impossível separar a ideia de uma nova sociedade, de um projeto para o Brasil enquanto uma estratégia de luta, da ideia de uma civilização da solidariedade, de uma nova matriz energética, um novo paradigma de civilização alternativo (THOMAZ JUNIOR, 2011, p. 15).

A luta por uma nova sociedade, que seja mais justa com os(as) que produzem sua riqueza, faz-se necessária e a universidade participa desse processo, sendo nesse sentido que esperamos que a pesquisa ora apresentada seja relevante.

\section{AS ESTTRATÉGIAS DA PRECARIZAC̣ÃO - DA FÁBRICA À VIDA COTIDIANA}

Autores como Antunes (2009), Alves (2011 e 2013), Harvey (1992) e Pochamam (1999) têm se dedicado a compreender as transformações promovidas no mundo do trabalho desde a Revolução Industrial e, mais especificamente, as transformações ocorridas no período da acumulação flexível. Pesquisas mostram que, desde o fordismo, a organização do trabalho nas fábricas alterou-se significativamente, passando do que Harvey (1992) chama de produção rígida para produção flexível, saindo da produção em série e com grandes estoques para uma produção que atende a interesses pré-determinados de consumidores no sistema de economia de espaço com estoques, o sistema kanbam. O fordismo foi o modelo que organizou a produção por longos anos, mantendo os níveis de acumulação em alta até meados do século XX, sustentado pela participação ativa do Estado na regulação da economia e no auxílio ao mercado. É interessante acrescentar que já então havia um forte trabalho no sentido da captura da subjetividade do trabalhador através de ações do Estado, que moldava padrões de família, consumo, lazer etc.

No sistema flexível, as mudanças aconteceram em função do esgotamento do modelo fordista, não eliminando totalmente suas práticas, mas inovando na organização do trabalho, articulando velhas práticas com novas necessidades. Nas fábricas, por exemplo, a produção atualmente restringe-se à montagem de peças que são fabricadas em várias partes do mundo, o que ajuda a economizar no 
investimento em espaço para as instalações fabris. A robotização, principalmente em montadoras, ressignificou o processo produtivo possibilitando uma extração de mais valia absoluta em larga escala e colocando o(a) trabalhador(a) na lógica da máquina, adequando, para tanto, seu corpo, seu ritmo, seu tempo, heranças melhoradas do sistema fordista de normatização do trabalho.

$\mathrm{Na}$ empresa onde se realiza a pesquisa - a MMC Motors - existem dois mil trabalhadores(as) que realizam atividades em vários setores. Na linha de montagem, observamos claramente a característica da acumulação flexível com a otimização dos espaços e várias políticas para "educar" o(a) trabalhador(a) a usar racionalmente o espaço da fábrica e os equipamentos. Um exemplo são os rigorosos horários seguidos pelo(a) trabalhador(a) que não são livres para, por exemplo, irem ao banheiro quando sentem necessidade, mas apenas ao final de um ciclo da linha de montagem.

Há, ainda, uma política de participação nos lucros da empresa e um sistema de banco de horas para os(as) trabalhadores(as), confirmando a intenção de manter o trabalhador sob domínio, evitando questionamentos sobre a exploração ou sobre os ganhos da empresa. A participação nos lucros (PLR) é um poderoso instrumento de dominação, uma vez que são poucas as empresas na cidade que "oferecem" esta política, que também, é claro, movimenta a economia local, principalmente o comércio. Os(as) trabalhadores(as) apontam a PLR como um dos mais importantes elementos de satisfação com a empresa.

Outro elemento dessa política é a divisão da equipe em grupos de produção coletiva - ou seja, é estabelecida uma meta para cada grupo, que precisa trabalhar em conjunto para alcançá-la; no entanto, se algum(a) funcionário(a) faltar por qualquer razão, a produtividade do grupo fica comprometida, caracterizando uma competição interna que contribui com a fragmentação dos(as) trabalhadores(as). Esta prática faz com que se estabeleça um ambiente marcado pela cobrança que se coloca entre os(as) próprios(as) companheiros(as) na linha de produção, pelo vigiar o outro, sua produção e seu ritmo. A punição também está presente, já que há uma transferência do fracasso da equipe para o indivíduo que, por alguma razão, não conseguiu atingir a meta estabelecida.

Alves (2013, p. 91) apresenta um resumo do metabolismo do novo (e precário) mundo do trabalho no Brasil na década de 2000. É importante lembrar que são caraterísticas gerais que sofrem a interferência dos lugares onde são estabelecidas, mas que podem ser observadas em larga escala. São elas:

- complexo de máquinas informacionais;

- a rede digital permeando trabalho, cotidiano e consumo (geração y);

- novos métodos de gestão e organização do trabalho (espírito do toyotismo e "captura" da subjetividade da força de trabalho); 
- coletivos geracionais híbridos do trabalho reestruturado;

- planos de demissão voluntária e dowsizing;

- novas relações flexíveis de trabalho; e

- novas formas de contratação, remuneração salarial e jornada de trabalho.

As caraterísticas apresentadas pelo autor podem ser observadas no local da pesquisa e, em um segundo momento, na vida cotidiana dos(as) trabalhadores(as). Segundo Santos (1996), nesse processo o sistema técnico científico informacional estabelece, sem dúvida, uma lógica nova, outro tempo, mais rápido e fluido, adequado ao sistema produtivo e exigindo do(a) trabalhador(a) novas estratégias de formação e capacitação. As novas lógicas espaciais de produção exigem cada vez mais conhecimentos diversos e não uma especialização em apenas uma área; além disso, há uma necessidade constante de informação e formação digital.

Acrescentamos a essa lista a prática da suspensão temporária dos contratos de trabalho com parte dos salários sendo pagos pelo Estado - o layoff, prática que tem sido comum em montadoras de todo o país e revela-se uma excelente estratégia, pois isenta a empresa de recolher tributos trabalhistas durante o período de vigência, que pode ser de até seis meses. Neste mesmo período, o trabalhador participa de cursos de formação e aperfeiçoamento ofertados pelo Estado, mas que não garantem a permanência no emprego.

As leituras dos pontos que culminaram na análise do atual quadro de precarização do trabalho podem ser as mais diversas. Contudo, a apropriação do ser genérico que trabalha em níveis externos e internos ao chão da fábrica, sua apropriação e de seu espaço, bem como da sua vida, não se revela apenas à luz da estrutura organizacional da fábrica, mas em sua vida cotidiana, elemento que pretendemos explorar na pesquisa. Ainda de acordo com Alves,

Portanto, além de novo arcabouço técnico-organizacional do capital, com suas novas máquinas informacionais, novos métodos de gestão de pessoas e novos locais de trabalho reestruturados com seu novo perfil etário-geracional, temos alterações das relações de trabalho que contribuíram para mudanças substanciais no metabolismo social do trabalho; isto é, os novos operários e empregados dos locais de trabalho reestruturados prostram-se diante da nova condição salarial que incorpora a adoção da remuneração flexível (PLR), jornada de trabalho flexível (banco de horas), contrato de trabalho flexível (contrato por tempo determinado e tempo parcial, além da terceirização) (ALVES, 2013, p. 91).

Assim, observamos como o capital global territorializa-se em todos os lugares, levando a sua lógica e transformando a vida de trabalhadores e trabalhadoras, como em Catalão. A nova lógica de trabalho programa uma rotina cada vez mais alienante que faz do(a) trabalhador(a) ainda mais dependente das 
regras do capital para sobreviver. A PLR é um exemplo disso, já que muitos(as) trabalhadores(as) acreditam que participam nos lucros da empresa e, por isso, não há exploração de sua força de trabalho.

O banco de horas também altera a rotina do(a) trabalhador(a), que já não pode programar suas atividades sem atender aos interesses da empresa e é obrigado(a) a ficar vários dias sem trabalhar para conter gastos em determinados períodos e, em outros, fazer mais horas de trabalho sem direito a horas extras. A própria MMC Motors utiliza-se muito dessa estratégia: quando o lucro diminui, estabelece férias coletivas ou recorre ao banco de horas.

A terceirização é outra faceta do processo de reestruturação produtiva e provoca o corte de vários postos de trabalho na matriz das empresas onde os direitos trabalhistas conquistados pelos sindicatos enfrentam dificuldade de alteração, como plano de saúde, abono, PLR, transporte, alimentação etc. Em Catalão, a MMC Motors e outras empresas terceirizam as áreas de limpeza, alimentação, segurança, manutenção de áreas externas, trabalhos de escritório, transporte e outros. Tal realidade fez com que observássemos um crescimento considerável no número de empresas prestadoras de serviços na cidade, aumentando a rede de interferências do capital global no lugar e reordenando as ações.

A terceirização promovida pela chegada do capital global ao lugar gera muitos empregos precários que são ocupados por trabalhadores(as) da cidade, enquanto os postos com melhor remuneração, ligados diretamente a cargos de comando, supervisão, gerenciamento etc, são ocupados pela mão de obra que migra acompanhando o deslocamento do capital. Os contratos temporários também crescem nos lugares com uma economia cada vez mais articulada, em que todos os setores se sustentam. A geração de postos de trabalho é o grande argumento do capital e ofusca todas as explorações, como se observa nos discursos a favor dos incentivos fiscais e no caso de Catalão.

Todos esses processos são responsáveis pelo adoecimento cada vez maior de trabalhadores e trabalhadoras em todo o país. As jornadas de trabalho intensas, a incerteza do emprego, a exigência de qualificação, de produção estão sugando do(a) trabalhador(a) todas as energias e, muitas vezes, toda a vida passa a ser dedicada ao capital, mesmo fora da fábrica ou de outros locais de trabalho. Um exemplo são as horas destinadas à locomoção de casa para o local de trabalho e o ritmo intenso promovido pela lógica do complexo de máquinas informacionais. Outro exemplo é a rede digital que nos coloca o tempo todo online e sempre prontos a responder correspondências e tarefas imediatas. Com essa conectividade, o tempo do trabalho invade cada vez o tempo do não trabalho, do lazer e do descanso do(a) trabalhador(a).

Apresenta-se, como exemplo dessa apropriação do(a) trabalhador(a) para além da fábrica, o caso de um trabalhador que estuda após a jornada de trabalho, 
em busca de uma qualificação cada vez mais exigida pela acumulação flexível. Ele(a) inicia sua jornada na fábrica às sete horas da manhã, onde permanece até às dezessete horas, de segunda a sexta-feira; ao sair do espaço da fábrica, toma um ônibus para a cidade de Uberlândia - MG, a cento e dez quilômetros de distância, onde frequenta aulas em uma universidade particular. Este(a) trabalhador(a) só retornará à sua casa por volta de meia-noite, provavelmente exausto e com tempo apenas para se reabilitar para a jornada do dia seguinte. $\mathrm{O}(\mathrm{a})$ trabalhador(a) é privado de outras atividades, como o lazer e o convívio com a família, enquanto busca alternativas para não sair do emprego atual ou se inserir em outro com melhor remuneração, o que nem sempre acontece. Nesse sentido, Alves argumenta que

As novas relações flexíveis de trabalho promovem mudanças significativas no metabolismo social do trabalho, tendo em vista que alteram a relação "tempo de vida/ tempo de trabalho" e alteram os espectros da sociabilidade e de autorreferência, elementos compositivos do processo de formação do sujeito humano-genérico. São as relações flexíveis do trabalho que instauram a nova condição salarial que impõem novas determinações no processo de precarização do homem que trabalha (ALVES, 2013, p. 92).

Observa-se, então, que cada vez mais o(a) trabalhador(a) dedica-se ao trabalho formal dentro da empresa e que, mesmo fora dela, o tempo do trabalho o persegue. Atividades simples do dia a dia têm que ser proteladas, adiadas, substituídas. Isso tudo aumenta a rede de precarização do trabalho, já que muitas vezes é, no caso das trabalhadoras, outra mulher que realiza algumas atividades domésticas ou de cuidados com a família por uma remuneração muito pequena, sem direitos trabalhistas etc.

Essa desregulamentação do trabalho provoca neste(a) trabalhador(a), pai e mãe de família ou mesmo no(a) trabalhador(a) estudante, inquietações, angústias, medos os mais diversos, que, por sua vez, interferem diretamente na vida do pai, da mãe, do marido, da esposa, do amigo, da amiga, do estudante, materializando-se em todos os locais por onde este(a) trabalhador(a) passa, pois não se separa o indivíduo das suas preocupações e dos seus medos.

Aí entendemos que há a materialização da desregulamentação em outros espaços, o que justifica a necessidade de se buscar compreender a precarização física e mental do indivíduo que trabalha no contexto atual da precarização do trabalho na cidade de Catalão - GO.

$\mathrm{O}$ contexto exposto remete-nos ao questionamento inicial de que o(a) trabalhador(a) é, hoje e com mais intensidade do que em outros momentos, a ferramenta que absorve os resultados da crise. E, atualmente, coloca-se também como sendo o(a) responsável por esta, principalmente devido às suas necessidades de consumo. No ano de 2015, observamos claramente isso na política de 
contenção de gastos da MMC - Motors, com a demissão de mais de seiscentos trabalhadores(as) da fábrica de Catalão; em um momento de crise mundial marcada pela recessão de mercados, a necessidade de não deixar de lucrar impõe a conta ao(a) trabalhador(a), estabelecendo um cenário de desespero entre os(as) demitidos(as) e de medo entre os(as) que permaneceram, sem saber ao certo até quando serão úteis à empresa à qual dedicam a sua vida produtiva dentro e fora da fábrica.

Contudo, ao passo que o(a) trabalhador(a) com o caráter flexível vem sendo responsabilizado(a) pelas falhas estruturais do sistema produtor de mercadorias, a sua vida vem sendo apropriada por esta tarefa, obrigando-o(a) a moldar-se para estancar tais falhas, hora com maior intensidade ou volume, hora com menor intensidade ou volume. Assim, no ano de 2015 foram registradas várias demissões em massa em montadoras de veículos no país, em um momento de crise no sistema de acumulação flexível e de revisão do papel do Estado na economia.

A vida do(a) trabalhador(a) ainda é marcada pelas estratégias de programação de consumo que o(a) colocam na condição de alimentador(a) do sistema financeiro através do crédito, com habitação ou com aquisição de mercadorias de toda espécie. Muitos(as) dos(as) trabalhadores(as) possuem seu salário comprometido com parcelas, financiamentos, carnês e boletos bancários, o que só reforça a submissão no espaço de trabalho. Comprometido(a), o(a) trabalhador(a) está sempre na luta pela manutenção do seu emprego, mesmo que cada vez mais precário, e o medo do desemprego torna-se uma constante em sua vida cotidiana, produzindo a miséria nas relações.

Um paradoxo se impõe: se está empregado(a), o(a) trabalhador(a) dedica o seu corpo ao processo produtivo, o que gera muitas doenças, como mostram as estatísticas disponíveis e vários estudos, como os de Alves (2013). O medo do desemprego também adoece, pois é uma constante na vida do(a) trabalhador(a). Se está desempregado(a), adoece em função das preocupações com o seu sustento e de sua família. Se estiver em um emprego temporário, convive com a incerteza do amanhã e se está em uma atividade informal, convive com a pressão do Estado e da polícia.

Dessa forma, temos uma relação de poder desigual, com a vitória do valor de troca sobre o uso. Carlos (2001) argumenta que:

A fluidez do tempo elimina a sensação do que dura e persiste, criando um vazio preenchido por coações. O poder controla o fluxo, o uso e o tempo do uso dos lugares. Assiste-se, assim, à constituição da identidade abstrata, produzida como consequência da extensão do mundo da mercadoria, que invade e transfigura a vida cotidiana, em que os signos proporcionam o modelo para manipular pessoas e consciências, organizando as relações sociais direcionadas pelo consumo do espetáculo (CARLOS, 2001, p. 37). 
Assim, um cotidiano marcado pelas relações rasas do consumo do espetáculo, além da manipulação das pessoas e consciências, também estabelece um esvaziamento dos movimentos organizados de trabalhadores(as) em todo o mundo. Este processo tem reflexos diretos nos usos dos espaços e na sua produção, já que insipra no(a) trabalhador(a) em situação de desigualdade a luta por seus direitos. A vida cotidiana transfigurada e marcada pela miséria das relações deixa poucos espaços para um projeto coletivo de luta, o que enfraquece os sindicatos e a participação em outras demandas sociais, como habitação, saúde, lazer e educação. "O corpo e os passos estão cada vez mais restritos a lugares vigiados, normatizados, privatizados ou privados" (CARLOS, 2001, p. 37), dentro da fábrica ou fora dela.

Nesse sentido, o(a) trabalhador(a) do limiar do século XXI é posicionado(a) em meio ao contexto que o(a) impede, na maior parte das vezes, de buscar uma participação efetiva na constituição de uma classe trabalhadora atuante no que tange às suas carências. A participação no movimento sindical e em outros movimentos é cerceada mesmo pelo cansaço físico, pela falta de tempo, pelas estratégias do capital.

No entanto, a dialética nos mostra que sempre há a contradição. Nesses mesmos espaços cerceados, vigiados, programados, a vida explode e revela caminhos que apontam para a emancipação. No caso da pesquisa em questão, uma emancipação que dialoga com a reprodução do urbano como um modo de vida que revela as frestas por onde passa o desejo, o que não foi capturado, a vida que não pode ser contida, o que escapa à programação, “[...] guardando o sentido do dinamismo das relações entre necessidades e desejos, englobando também as ações que fogem ou se rebelam contra o 'poder estabelecido'" (CARLOS, 2001, p. 41). O desafio da pesquisa segue.

\section{RESULTADOS E CONCLUSÕES}

Ao longo dos últimos anos, inúmeras questões acerca da precarização do trabalho têm sido levantadas, questões que colocam o(a) trabalhador(a) em um contínuo movimento que o conduz ao encontro das perdas dos direitos trabalhistas. Esse contexto tem, ao longo desses anos, nos inquietado e impulsionado no sentido da compreensão desse movimento. Entender a lógica da reprodução do capital em nível global, articulado ao lugar, revela as estratégias espaciais de programação, normatização, padronização e homogeneidade.

O espaço de trabalho encontra-se cada vez mais articulado para intensificar o ritmo da produção e da circulação de mercadorias. Na fábrica, a flexibilização do mundo do trabalho racionaliza mais ainda o uso do tempo e de espaços, aprisionando o corpo do(a) trabalhador(a) cotidianamente. A acumulação de capital 
só pode acontecer pelo trabalho e pela extração de mais valia e, nesse sentido, a acumulação flexível coloca-se como uma estratégia para superar a crise do final do século XX, produzindo a custos mais baixos e retirando direitos trabalhistas.

Hoje, todo o contexto de precarização no chão de fábrica se intensificou com ações como a terceirização, o trabalho temporário e a informalidade, dentre outros; todavia, observa-se o avanço da precarização do trabalho na vida do(a) trabalhador(a) para além da fábrica, movimento que é proporcionado pela intensificação no processo produtor de mercadorias, que não se sustenta sem a exploração do trabalho.

Em contrapartida, o(a) trabalhador(a) que se insere no mercado produtor de mercadorias e é obrigado a alcançar altos níveis de produção, constitui-se, também, como consumidor desta mercadoria, inserindo-se em um círculo vicioso. $\mathrm{O}$ crédito para o(a) trabalhador(a) e programas de financiamento de habitação, automóveis e produtos diversos são fundamentais para gerar lucros ao capital e manter endividados tais trabalhadores(as). No ano de 2015, os(as) trabalhadores(as) da MMC - Motors vivem um momento de crise mundial e lutam contra a demissão em massa através do Sindicato dos Metalúrgicos de Catalão e movimentos sociais constituídos na cidade e no campo. Após cortar gastos com custos de produção, explorando ao máximo o(a) trabalhador(a), agora é hora de a empresa cortar postos de trabalho.

$\mathrm{O}(\mathrm{a})$ trabalhador(a) é responsabilizado pelo fato de o mercado se encontrar fragilizado devido aos baixos índices de produtividade ou à elevação dos custos de produção, e não há uma perspectiva de cortes de lucros, apenas cortes relativos à mão de obra. Em Catalão foram demitidos, até o momento, 600 trabalhadores(as) da montadora MMC - Motors, e ainda há previsão de mais demissões em até o fim de 2015; cabe lembrar que a cadeia produtiva toda é afetada e outros(as) trabalhadores(as) também serão demitidos(as). A cidade toda vive o impacto dessa estratégia global na economia local.

A mesma realidade é vivida em outras cidades do país onde existem montadoras como a FIAT, General Motors (GM) e Volkswagen (VW), onde trabalhadores(as) perdem o emprego após anos de dedicação à empresa. Em alguns casos, foram demitidas duas pessoas da mesma família, com necessidades especiais, prestes a se aposentarem, e nem todas conseguiram uma recolocação no mercado em função da especificidade de sua formação laboral.

Esse é o contexto que programa um(a) trabalhador(a) de acordo com o mercado, precarizado(a) pela natureza destrutiva do capital que se realiza, não apenas na fábrica, mas em outros lugares de sua vida. A precarização adoece e degrada o cotidiano do(a) trabalhador(a), impondo a miséria e as necessidades urgentes e deixando muitos(as) fora do mercado formal de trabalho, sem direitos trabalhistas e garantias de uma aposentadoria. 
O sindicato local, filiado à Força Sindical, constrói uma estratégia de enfrentamento na luta contra as demissões realizadas e contra novas demissões, mas possui muitas dificuldades em negociar. Momentos de ação e mobilização são promovidos e há grande participação de trabalhadores(as). A montadora argumenta ser preciso que o mercado se recupere da crise para vender seus estoques e, então, voltar a produzir, recuperando alguns postos de trabalho. E o impasse se mantém.

Nesse movimento de captura da subjetividade do(a) trabalhador(a), há o que escapa, que não é capturado na reprodução da vida cotidiana: a riqueza da vida. Como potencializar essas ações na construção da luta operária? Que estratégias de classe utilizar nesse enfrentamento? A pesquisa pretende contribuir com o esclarecimento de tais questões.

\section{REFERÊNCIAS}

ALVES, G. Trabalho e subjetividade: o espírito do toyotismo na era do capitalismo manipulatório. São Paulo: Boitempo, 2011.

. Dimensões da precarização do trabalho: ensaios de sociologia do trabalho. Bauru: Canal 6, 2013.

ANTUNES, R. Os sentidos do trabalho: ensaios sobre a afirmação e a negação do trabalho. 2 ed. São Paulo: Boitempo, 2009.

CARLOS, A. F. Espaço-tempo na metrópole. São Paulo: Contexto Acadêmica, 2001.

HARVEY, D. Condição pós-moderna. 21. ed. São Paulo: Loyola, 1992.

NOGUEIRA, C. M. O trabalho duplicado: a divisão sexual no trabalho e na reprodução

- um estudo das trabalhadoras do telemarketing. São Paulo: Expressão Popular, 2006.

POCHMANN, M. O trabalho sob fogo cruzado. São Paulo: Contexto, 1999.

SANTOS, M. A natureza do espaço: técnica e tempo, razão e emoção. São Paulo: Hucitec, 1996.

THOMAZ JUNIOR, A. O mundo do trabalho e as transformações territoriais: os limites da leitura geografia. Revista Pegada, Presidente Prudente, v. 12, n. 1, jun. 2011. 
